\title{
External accountability of collaborative arrangements; a case study of a Multi Academy Trust in England
}

\author{
Melanie C. M. Ehren $^{1}$ (D) David Godfrey ${ }^{1}$
}

Received: 6 March 2017 / Accepted: 21 July 2017 / Published online: 4 August 2017

(C) The Author(s) 2017. This article is an open access publication

\begin{abstract}
This paper explores the impact of external accountability on four mechanisms of network-internal quality control and the properties of (mandated) interorganizational networks. An explorative case study approach examines the external accountability of a newly established educational network (MAT) and how schools and the Trust are held accountable by the English Inspectorate of Education, Ofsted and the Department for Education (DfE), through Regional Schools Commissioners (RSCs). Analysis of documents and interviews were used to reconstruct a sequence of events over a period of five and a half years. Our findings indicate that the combination of accountability activities led to more centralized control over, and monitoring of curriculum, assessment and school improvement. This was accompanied by a pause in the growth of the Trust and the establishment of a regional structure of school collaboration. As accountability is particularly organized around individual school performance (through Ofsted inspections), this limited development of internal mechanisms of quality control around network-level outcomes. A short-term focus dominated the allocation of resources to schools in special measures or with an upcoming inspection visit. In the discussion, an alternative model is presented for network-level accountability and a set of indicators for effective accountability of collaborative arrangements.
\end{abstract}

Keywords Accountability $\cdot$ School networks $\cdot$ Inspections $\cdot$ School improvement $\cdot$ MultiAcademy Trusts

This study was funded by the EU Erasmus+, funding ID 2014-1-UK01-KA200-001798

Melanie C. M. Ehren

m.ehren@ucl.ac.uk

1 Institute of Education, University College London, 20 Bedford Way, London WC1H 0AL, UK 


\section{Introduction}

Many governments recognize the limitations of centralized policy in motivating school improvement and turn to "network governance" to coordinate school systems (Janssens and Ehren 2016). Network governance is described by Meuleman (2008) as the third form of governance, emerging in the 1990s out of the dominant hierarchical-control and market-governance styles of the time. Network governance involves policies that link different stakeholder organizations around a public policy purpose and a set of joint goals (Mayne and Rieper 2003) such as preventing drop-out of students in their transitioning from lower to upper secondary education.

Government policy in England has followed the trend of increased network governance in incentivizing a range of school-to-school partnerships, particularly the model of a "Multi-Academy Trust" (MAT). MATs are chains of publicly funded independent schools (academies) which are run by a Trust (Board of Directors). Academies and their Trust must follow the law and guidance on admissions, exclusions and special education needs and disabilities, but benefit from greater freedom. ${ }^{1}$ They can set pay and conditions for their staff, decide on how to deliver the curriculum and they have the ability to change the length of terms and set their own school hours.

"MATs are the only structures which formally bring together leadership, autonomy, funding and accountability across a group of academies in an enduring way, and are the best long term formal arrangement for stronger schools to support the improvement of weaker schools." (DfE 2016, p. 57).

In 2012, there were 312 academy chains in England, with 39\% of the academies being part of a chain. By 2015, nearly two thirds of the 4725 academies were in MATs and 517 MATs had 2 to 5 academies, 98 with 6-15 and 19 MATs with 16 or more or schools (some up to as many as 66 schools), located in different regions across England.

Popp et al. (2014) summarize the benefits of inter-organizational networks, such as MATs, as sharing risks, innovation, flexibility and responsiveness. According to Gray et al. (2003), networks can create synergy when the partnership adds value by combining mutually reinforcing interests, can transform different views into an ideological consensus or can enhance (financial) efficiency when the use of resources is maximized across the partners in the network. Bringing actors together who depend on one another in delivering services can increase the effectiveness of these services according to Klijn and Koppejan (2014) and is expected to be an answer to complex policy problems where actors need one another's resources to achieve solutions. Popp et al. (2014) further suggest that the creation of inter-organizational networks can be a strategy for developing a structure that is more nimble and able to effect change than bureaucratic

\footnotetext{
${ }^{1}$ Local authorities however remain responsible for Special Educational Needs and Safeguarding of pupils both in their maintained schools as in academies, but they need to voice concerns about these (and other issues) in academies to the Secretary of State (see Department for Education, May 2014, Schools causing concern; Statutory guidance for local authorities).
} 
organizations under centralized hierarchical control. The UK government's reference to a "self-improving system" indicates that it has similar ambitions with the introduction of MATs (DfE 2016).

Klijn and Koppejan (2014) describe how there is a growing need to hold networks such as MATs, to account, especially where concerns have been raised with respect to their behaviour and performance. A recent inquiry of MATs by the UK Education Select Committee posed questions around the effectiveness and efficiency of Trusts, referencing press coverage of excessive pay rises of CEOs of Trusts (e.g. Schools Week, March 11, 2016). Popp et al. (2014) describe how strong ongoing monitoring and evaluation of networks from the earliest stages of their development is an important strategy for identifying and addressing any unintended negative consequences of interorganizational networks.

The accountability of networks is however problematic due to the diffuse and ambiguous nature of collaborative arrangements, the changing (contribution of members to) network-level outcomes and the sometimes conflicting expectations of stakeholder and client groups. Several authors (Mayne and Rieper 2003; Schwartz 2003; Janssens and Ehren 2016) explain how the aims and objectives of networks are often not centrally defined, but result from collaborative efforts and fragile compromises between partners with different political, social and economic aims. Such issues complicate external accountability as most partners in a network will be ill at ease with being held to account for something they do not have complete control over. Traditional top-down models of accountability will have great difficulty in disentangling how being in the network has impacted on the performance of its individual members, or to what extent each member has contributed to network-level outcomes. As Klijn and Koppejan (2014) point out, most accountability systems are firmly grounded in monocentric, state-oriented models of governance, which presuppose that "accountor" and "accountee" are known, coherent, straightforward entities embedded in a single and clear-cut governance system. When public policy is produced in complex networks featuring multiple, overlapping coordination mechanisms, the very identification and make up of accountability relationships becomes problematic (Romzek 2000). An important question is therefore how vertical accountability mechanisms can be designed or strengthened in such a way that they do not hinder or disturb the governance network processes, while complementing and reinforcing horizontal accountability mechanisms (see also Klijn and Koppejan 2014).

This paper explores the external accountability of MATs in England as a case study of how external accountability can be organized to address network functioning and performance. Our case study describes how the English Inspectorate of Education, Ofsted and the Department for Education (DfE) through Regional Schools Commissioners (RSCs) developed external inspections and monitoring of MATs. In our case study, we focus on how these arrangements influenced the development of one newly established nationally operating MAT over time, particularly their internal mechanisms for quality control and changes in the network properties of the MAT. In our conclusion and discussion, we will reflect on the system of external accountability of formal school-to-school networks and propose a set of indicators for effective accountability of collaborative arrangements. First we provide a description of networks and their internal quality control mechanisms. 


\section{Conceptual framework}

\subsection{Network properties}

"Networks" can simply refer to a collaboration of groups of three or more legally autonomous organizations that work together to achieve a collective goal (Kenis and Provan 2006), either self-initiated by network members, or mandated or contracted (see Klijn and Koppejan 2014). Mandated or contracted networks are goal-directed and will have more stable patterns of social relations, deliberate interactions and structure in their interactions with organizational arrangements and rules. MATs in England are typical examples of mandated networks as collaboration of schools within the Trust is regulated through funding agreements between MATs and the Secretary of State, and schemes of delegation and terms of reference which outline roles and responsibilities and decision-making within the Trust. All academies in a MAT are run by a single board of directors, although the Trust may decide to delegate some functions to schoollevel governing bodies; the Trust however remains accountable for the schools and can take all decisions on how the schools are run. ${ }^{2}$ Each academy also has a supplemental funding agreement with the Secretary of State and their accountability is therefore ultimately to the Department for Education.

Berthod et al. (2016) explain that effectiveness of networks is a product of properties of the network, such as its governance mode, network structure and network context. Modes of governance can vary from not brokered shared governance to highly brokered by one organization, and from participant-led to externally led. Kenis and Provan (2006) distinguish between "shared governance" where the network is entirely governed by its members and every organization would interact with every other organization to govern the network, resulting in a dense and highly decentralized form. In the model of "network administrative organization governance", the network is governed by a unique network administrative organization (NAO), which may be either voluntarily established by network members or mandated as part of the network formation process. The administrative entity, which is typically a government entity or a nonprofit, is set up specifically to govern the network and the activities of the network and the NAO acts as a broker in coordinating and sustaining the network; the NAO is not a member of the network. The third model of "lead organization governance" is similar in having a brokered form of governance, but the lead partner in this model is another member organization who is providing its own services as part of the network. MATs would typically have a lead organization (one of the outstanding schools in the network) or administrative organization (Trust head office) govern the network.

As Provan and Kenis (2008) explain, modes of governance change over time as networks evolve and grow in number of members; the adoption of a particular form of network governance should be contingent on the trust distribution among network participants, the number of participants, goal consensus and the nature of tasks. They argue that as trust becomes less densely distributed throughout the network, as the

\footnotetext{
$\overline{2}$ http://www.parliament.uk/documents/commons-committees/Education/report-education-academies-andschools.pdf
} 
number of participants gets larger, as network goal consensus declines and as the need for competencies required to achieve network-level goals increases (e.g. skills to coordinate the network), brokered forms of network governance (lead organization and NAO) are likely to become more effective than shared-governance networks. According to Berthod et al. (2016) and Hu et al. (2015), larger networks will struggle to have effective forms of bottom-up shared governance as members will either ignore critical network issues or spend large amounts of time trying to coordinate across 10, 20 or more organizations, particularly when participants are spread out geographically. Larger networks often also face problems with the distribution of trust across the network and with ensuring goal consensus. Such large networks are therefore more effective, according to Provan and Kenis (2008), with brokered forms of network governance, where a separate administrative entity governs the network and its activities. Shared governance is most likely to be effective when trust is pervasive throughout the network and provides a strong basis for bottom-up collaboration among network members, whereas bottom-up initiated collaboration is, according to Provan and Kenis (2008), less essential in more centralized networks where a lead organization coordinates collaboration through dyadic ties with individual members. Research on inter-organizational networks suggests that most networks move from participant-based governance to governance via lead organizations or network administration when networks increase in size and heterogeneity (Provan and Kenis 2008).

\subsection{External accountability}

In defining accountability, we use Klijn and Koppejan's definition (Klijn and Koppejan 2014 , p. 2) who talk about accountability as "the extent to which actors (accounters: those rendering accounts) are held accountable for their behaviour and performance by other actors (accountees: those to whom account is rendered)". The actors in our study are the schools within a MAT, the central staff and the board of directors of the Trust who are held accountable for the quality of education and performance of children by the Department for Education. Accountability involves both a process by which the accounter renders account to the accountee, and accountability mechanisms, i.e. the procedures, instruments and arrangements by which an account is given (Klijn and Koppejan 2014). The latter also includes standards of what is considered to be appropriate behaviour and rules, reflecting norms and values.

The accountability of MATs is primarily organized through Ofsted inspections of both individual schools and the Trust, in Focused Inspections (FIs, also called "batched inspections") and a MAT review, as well as through the monitoring of schools and the Trust by Regional Schools Commissioners, acting on behalf of the Department for Education. Although Ofsted is, under current legislation, only allowed to inspect schools with a Unique Reference Number (URN), FIs were introduced in $2014^{3}$ to allow for an evaluation of MATs beyond the quality of each individual school. Ofsted's takes its remit for FIs from the inspection framework of individual schools ${ }^{4}$ which explains how in principle a good school may be inspected once every 5 years, an exemption to which can

\footnotetext{
${ }^{3}$ The first outcome letter of a FI was published 25 March 2014 of E-ACT.

${ }^{4}$ http://www.ofsted.gov.uk/resources/framework-for-school-inspection
} 
be made when the school is part of a formal grouping of schools such as a MAT and shares important aspects of its provision. In this case, Ofsted considers it appropriate to inspect several schools in the group at the same time in a FI.

There is no framework for such inspections, but guidelines point out that FIs include coordinated visits to all the schools in a Trust, looking at differences and common issues between schools in analysing questionnaires from students, parents and staff. Common issues across schools are shared and discussed between the lead inspectors during the inspection week(s), particularly with a view to discuss any features that could lead to common areas for further improvement relating to the impact of the Trust. Schools are questioned about the level of support and challenge from the central office and their collaboration with other schools in the Trust; school-to-school collaboration is seen as an important element of school leadership and the school grade for this inspection standard reflects the extent to which the school engages in collaboration with other schools.

At the end of a FI (typically in the second or third week), Her Majesty's Inspectors ${ }^{5}$ (HMIs) also interview members from the central staff and a selection of headteachers of schools within the Trust, and analyse documents from the Trust to review the functioning of the Trust. The FI and the MAT review leads to an outcome letter which describes the strengths and weaknesses of academies across the Trust and the impact of the Trust's leadership on the individual academies.

The Regional Schools Commissioners also have an important role in the set up and monitoring of academies and MATs. They were introduced in 2014 to coordinate the setup of academies and MATs and to monitor their performance on behalf of the Department for Education. RSCs are responsible for the academies in their area and make decisions on applications from schools wanting to become academies and organizations wanting to sponsor an academy. Each RSC is also responsible for one of the larger national MATs (e.g. ARK, E-ACT). Their main responsibilities are to do the following ${ }^{6}$ :

- Monitor the performance of the academies in their area

- Take action when an academy is underperforming

- Decide on the creation of new academies

- Make recommendations to ministers about free school applications

- Encourage organizations to become academy sponsors (ensuring that there are enough high-quality sponsors to meet local need, ensuring each region has a strong supply of high-quality sponsors)

- Proposing suitable sponsors for poorly performing maintained schools who have been selected by DfE to become sponsored academies.

- Approve changes to open academies, including the following: changes to age ranges, mergers between academies, changes to MAT arrangements

\footnotetext{
${ }^{5}$ HMI's are normally employed full-time by Ofsted as opposed to other contracted staff, many of whom work in schools in leadership positions. See http://www.ofstedhmi.co.uk/

${ }^{6}$ https://www.gov.uk/government/policies/increasing-the-number-of-academies-and-free-schools-to-create-abetter-and-more-diverse-school-system/supporting-pages/regional-schools-commissioners-rscs
} 
RSCs are particularly responsible for the oversight and monitoring of those academies which are in special measures or require improvement according to Ofsted. Where there is underperformance in an academy school or Trust, the RSC takes their authority from the funding agreement (the contract between the Secretary of State and the Trust). The RSCs decide solely on breaches of the funding agreement on the grounds of failure to deliver a good quality education; other potential breaches, such as conflicts of interest or financial mismanagement, are dealt with by the Education Funding Agency. The RSCs get support from headteacher boards (HTBs) which are made up of experienced academy headteachers in each region who advise and challenge RSCs. These headteachers are from outstanding academies and are elected by other academy headteachers in the region.

\subsection{Internal quality control in the network}

As networks grow and mature, the need for structured mechanisms of internal quality control also increases. Aviram (2003) refers to four mechanisms networks can use to enforce norms and regulate the behaviour and performance of members:

i. Information mechanisms; i.e. the collection and dissemination of information on the credibility and quality of network partners. This facilitates independent decisions on the contribution of members of the network to network-level outcomes and potential dysfunctional outcomes of collaboration, such as groupthink, high transaction costs, power struggles, diffusion of roles and responsibilities (see Mayne and Rieper 2003). An information mechanism allows members in the network (as well as those outside of it) to make informed decisions on who to collaborate with in the network, and on excluding partners who act opportunistically, degrade the overall performance of the network or destroy its reputation. Peer reviews between schools within MATs, and reviews of the quality of central services are examples such information mechanisms. These can show, for instance, whether some schools bias their admission processes to favour students from privileged backgrounds, or if the Trust takes too many failing schools requiring high levels of central support.

ii. Exclusion mechanisms; in mature networks there are formal and transparent procedures to deny members access, either permanently or temporarily. Aviram (2003) describes how the threat of expulsion or suspension will ensure the compliance of each member to the norms of the network. In England, this mechanism mainly operates through the RSCs who are in charge of removing schools from a Trust or re-brokering schools into other Trusts in the case of failing performance or after the funding agreement expires. Several authors (Hill 2008; Greany and Ehren 2016) argue for greater clarity in these procedures, particularly of the criteria used to re-broker schools, and also for shorter timelines of funding agreements (from 7 to 5 years) to allow academies to move between Trusts more easily.

iii. Centralized control over facilities required for transactions between network members and control over members' assets enforces members' compliance to network-norms and contribution to network-level outcomes. In our case, this 
concerns collaboration between schools and Trust central staff support of schools. Centralized control is a preventative mechanism, in that it allows the network to better monitor transactions for opportunism and possibly prevent or modify these transactions (Aviram 2003). Control mechanisms may be employed in bilateral transactions such as between two schools, whereas large networks tend to have a centralized facility to control the transactions between its members. Examples with large MATs (16+ schools) include a central head office, implementing and monitoring systems of operational and financial planning, target setting, data tracking and performance management across schools in the Trust (see Hutchings et al. 2014). Some of these systems also include centralized planning of teaching and learning through the prescription of curricula, lesson planning, time tabling and assessment schemes. The development and implementation of these systems is paid for by top slicing a percentage of the schools' budgets.

iv. Switching mechanisms (Aviram 2003) replace defaulted transactions with alternative ones or find alternative members for those excluded. For MATs this could mean replacing schools re-brokered into other Trusts, or switching ineffective forms of school-to-school collaboration with more effective ones.

These four mechanisms for internal quality control are important for the stability and the performance of the network and its long-term survival (Mandell and Keast 2007). Aviram (2003) explains how these mechanisms support the development of successful collaboration, and the creation of a new organizational form that exists by itself, over and above its individual network members. Network participants feel part of this whole and no longer only loyal to their home school.

In this case study, we are interested in learning how external accountability impacts on these four mechanisms of internal quality control and the properties of (mandated) inter-organizational networks (governance, size and growth).

\section{Methodology}

We employed an explorative case study approach to capture the way in which external accountability impacts on the functioning and performance of an inter-organizational network. Our in-depth, single case study allowed us to create a dataset going beyond the one-shot surveys or use of secondary data used in most research on public networks. This longitudinal dataset describes the network in action over a period of 5.5 years and reveals the changes in the functioning of the network and how these relate to (changing) external accountability. The selection of our case study MAT therefore informs an emerging theory about effective accountability of collaborative arrangements, and how to design such systems that address the complexities of inter-organizational collaboration.

Our case study MAT is currently one of the larger nationally organized Trusts. The Trust has a portfolio of primary and secondary schools and a central office providing back office services to its schools (e.g. HR and financial management), supporting schools and brokering collaboration between schools through a model which fits Provan and Kenis' (2008) description of "network administrative organization" governance. 


\subsection{Data collection}

The Trust received a FI in year 5, in addition to regular Ofsted school inspections, and regular RSC monitoring visits of academies within the Trust, and of the central head office. In our case study, we retrospectively analysed changes in response to these accountability interventions. Our period of study starts with the inception of the Trust in year 1 and ends in September year 6 .

We conducted interviews with those directly involved in the external accountability of the MAT (HMI, RSC), as well as interviews with headteachers of schools involved in the FI and the Trust CEO. Interview questions aimed to enhance our understanding of how specific accountability interventions (single school and focused inspections, RSC monitoring) had impacted on the properties of the network, and network-internal mechanisms of quality control. All the interviews were recorded and transcribed with prior consent of participants while findings are reported anonymously and without identifying information to protect the identity and reputation of the Trust, HMI and the RSC. As such, actual years for data have been changed to years 1-6, as have exact numbers of schools, years of Ofsted inspection reports and references to geographical locations. Interviews took place in the spring of year 5 .

Second, we collected archival material from the Trust and outcomes of external inspections and monitoring of schools and the Trust (e.g. Ofsted school reports, Ofsted outcome letter, RSC pre-warning notices). Archival material spanned a timeframe of 5.5 years, and was used to construct a database where events were recorded according to the main variables in our conceptual framework. Triangulating interviews and archival material provides some reassurance that interpretations are not shaped by an idiosyncratic account of events. Table 1 provides a summary of our data collection.

Table 1 Case study data collection

\begin{tabular}{|c|c|c|}
\hline HMI/RSC/DfE/EFA & Trust/central staff & Academies and free school in the trust \\
\hline $\begin{array}{l}\text { - Interview with National School } \\
\text { Commissioner and Regional } \\
\text { School Commissioner } \\
\text { - Group interview with } 6 \mathrm{HMI} \\
\text { (including lead inspector of FI) } \\
\text { - Interview with Ofsted director of } \\
\text { education policy } \\
\text { - Analysis of outcome letter of FI } \\
\text { year } 5 \\
\text { - Analysis of DfE notice letters to } \\
\text { academy trusts about poor or } \\
\text { inadequate performance or } \\
\text { weaknesses in safeguarding, } \\
\text { governance or } \\
\text { financialmanagement } \\
\text { (pre-warning notices to } 2 \\
\text { academies) } \\
\text { - Analysis of RSC websites }\end{array}$ & $\begin{array}{l}\text { - Interview with CEO of the trust } \\
\text { - Analysis of website, } 5 \text { annual } \\
\text { reports, Articles of } \\
\text { association, Master funding } \\
\text { agreement, Register of local } \\
\text { governing bodies, scheme of } \\
\text { delegation in year } 5\end{array}$ & $\begin{array}{l}\text { Analysis of website and all Ofsted } \\
\text { schoolinspection reports since } \\
\text { conversion to academy status of } \\
\text { all the schools that were part of } \\
\text { the Trust between years } 1 \text { and } 6 \\
\text { Interviews with } 6 \text { headteachers of } \\
\text { schools inspected as part of the } \\
\text { FI }\end{array}$ \\
\hline
\end{tabular}




\subsection{Data analysis}

Sequences of events served as the basis for our data analyses. Each interview and document was coded according to the variables in our conceptual framework in which we recorded events for 6-month intervals to provide a chronological timeline of changes in each of the variables between the inception of the Trust in year 1 and the end date of our study in September, year 6. Events were recorded for intervals of January to August, and September to December, taking into account the 2-month summer period (July-August) when schools are closed and generally no major changes are implemented. Events refer to actions, activities and policies that provide a time-stamped description of external accountability, internal quality control and properties of the network.

We used two phases to code our data and collate a database of chronological events. In the first phase, all the archival material and interviews were investigated for types of observations (e.g. activities, events, policies) within each variable. Our analysis resulted in a list of observations for each variable as shown in Table 2. Decisions were then made on how to classify specific activities, policies

Table 2 Specification of variables in activities, events and policies

\begin{tabular}{|c|c|}
\hline Variable & Events for case description \\
\hline External accountability & $\begin{array}{l}\text { Ofsted school inspections, FI and MAT review, RSC monitoring } \\
\text { of schools, RSC monitoring of the Trust (timing, judgement } \\
\text { and feedback on the functioning and performance of the Trust) }\end{array}$ \\
\hline \multicolumn{2}{|l|}{ Internal quality control } \\
\hline Information mechanism & $\begin{array}{l}\text { Changes in policies to implement Trust-wide peer reviews } \\
\text { and actual peer reviews in schools, external reviews of governance } \\
\text { of schools and of the network, Trust-level monitoring of academies } \\
\text { (timing and outcomes of these reviews, such as safeguarding visits, } \\
\text { performance monitoring, financial monitoring) }\end{array}$ \\
\hline Switching mechanism & $\begin{array}{l}\text { Changes in collaboration between schools and support provided } \\
\text { by the central staff }\end{array}$ \\
\hline Exclusion mechanism & $\begin{array}{l}\text { Transfer of schools to other Trusts, and brokering and re-brokering } \\
\text { schools through the RSC }\end{array}$ \\
\hline Control mechanism & $\begin{array}{l}\text { Changes in allocation of resources (membership fee) and coordinating } \\
\text { transactions between schools in working groups (coordination } \\
\text { of schools is described under governance) }\end{array}$ \\
\hline \multicolumn{2}{|l|}{ Network properties } \\
\hline Governance & $\begin{array}{l}\text { Changes in structure (e.g. introduction of regional structure, changes } \\
\text { in roles and responsibilities of central staff, schemes of delegation } \\
\text { and terms of reference, improvement boards with central staff), roll } \\
\text { out of centralized systems (e.g. common assessment policy, } \\
\text { common systems for financial planning and monitoring) }\end{array}$ \\
\hline Size and growth & (Increasing/declining) numbers of academies in the Trust \\
\hline Composition & $\begin{array}{l}\text { Primary/secondary, sponsored/new academies/free schools: voluntary } \\
\text { or forced brokering; location of schools and distances between } \\
\text { schools and the head office }\end{array}$ \\
\hline
\end{tabular}


and events, particularly those that could fall under multiple variables, such as the development and implementation of centralized performance monitoring, which is both an element of internal quality control, as well as a change in governance of the network. This specification of variables was then used to code all the materials according to time frame in phase 2 . In phase 3 , we validated the timeline of changes in an interview with the CEO of the Trust.

\section{Findings}

Our case study MAT started in year 1 with one secondary converter academy and grew over time with a peak in number of (both primary and secondary) schools in year 3/4. Schools are dispersed across the country in several different counties, some of the schools are in the same county as the head office, while others are located over 150 miles away.

\subsection{External accountability}

Inspections of schools Following the expansion of the Trust, there were regular school inspections and in several cases the initial inspection outcomes were disappointing. In the inspection reports, comments are made on where the Trust needs to improve and where its structures and support of individual academies has been more or less effective; recommendations are made on a range of issues. Identified priorities included developing better systems to monitor pupil performance and hold teachers and leaders to account, developing more specific school improvement actions plans, training subject leaders and reviewing the Trust's governance.

Focused inspection and MAT review The Trust received a FI and a MAT review in the first half of year 5. The FI included inspections of six academies and telephone interviews with the headteachers of the other academies. The CEO and headteachers who were part of the FIs explain how the Trust was not formally informed about the FI, but this became apparent as further schools were inspected in the same week and headteachers started calling each other and the head office. The MAT review was scheduled in the second week after the FI and included interviews with central staff and several headteachers, as well as further analysis of Trust documentation.

The outcome letter of the FI includes a range of strengths and weaknesses and recommendations, such as on the gathering and analysis of pupil outcomes and attendance (particularly of specific groups of pupils), how the headteacher performance management needs to include targets on the performance of vulnerable groups, and the development of a coherent cross-trust strategy to improve the support of, and provision for these pupils. The headteacher of Primrose academy explained how, contrary to school inspections, more credence is given to development plans instead of (only) outcomes and current practice. The head teacher of Campanula further expressed caution in criticizing the Trust as she felt it might impact on the school's own inspection outcome, and she felt it was important to "toe the party line". 
RSC monitoring of schools In addition to Ofsted, RSCs have become an important part of the accountability regime for all academies. Before 2014, monitoring by the DfE primarily included visits to new (free) schools. From 2014 onwards, with the start of RSCs, monitoring was expanded to include academies failing to deliver good education, defined as not meeting targets for student performance on national standardized assessments (Key Stage 2 or 4 floor standards), being on a downwards trajectory or judged to be inadequate by Ofsted ("requires improvement" or "special measures").

Academies and a free school in the Trust received RSC monitoring visits shortly after their opening or Ofsted inspection, two of the academies received a pre-warming notice.

The respective RSCs and the Trust discussed the restructuring of the Trust schools in order to make the schools more geographically coherent and thereby increase the level of support for school improvement. Between years 1 and 6 , the RSC re-brokered a number of schools into other Trusts.

Headteachers refer to RSC's as "the DfE", or "educational advisors", and are not always clear about who was visiting the school, who sent written reports or with whom they were communicated. There is no public record of monitoring activities and visits of the RSC or their educational advisors; however (according to the Headteacher of Foxglove Academy), a confidential letter or report to the school was provided for the central office of the Trust and governors of the school.

The lack of framework and variety of practices or guidelines for RSC visits caused anxiety and confusion in schools. The headteacher of Primrose also described these as far less rigorous compared to Ofsted inspections. On occasions, particularly in the early stages of their work, the RSC judgement of school effectiveness was at variance with the Ofsted view, and often more lenient, but, according to the headteacher of Amaryllis, RSC monitoring became more rigorous over time.

RSC monitoring of the Trust The CEO of the Trust explains how he and his education and financial director (from 2014 onwards) also have termly meetings with the RSC to discuss performance data and potential problems in schools. The meeting is informed by a risk analysis of key stage test performance data, predictions for future performance, pupil numbers in each school and Ofsted grades. Schools are highlighted in red, amber or green, or black to reflect their performance and areas of concern. The RSC will ask what kind of improvement package the Trust has in place for high risk schools. High risk schools are visited by (RSC related) advisors, or discussions with the EFA are brokered in case of budgetary problems. The RSC particularly looked at academies performing below the floor standards and action plans of those academies. In the meeting, targets are set for the Trust to improve schools where performance is low.

The schedule of inspections and external monitoring of the MAT predominantly focuses on individual school performance through inspections and RSC monitoring of individual schools. Monitoring of the Trust itself only began in year 4, consisting of the termly meetings and the focused inspections and MAT review. Consequently, individual school inspections are an important benchmark for performance of the Trust as the headteacher of Campanula Academy explains: 
"well obviously it's a benchmark isn't it, it's a marker for them [the Trust] to know how well their schools are doing. It's...I'm going to say a status symbol but I don't... well I do mean it, they do like to say we've got X amount of Outstanding schools, X amount of Good schools, of course they do, that's how they are viewed by the outside world. So it's important to them."

Below we will describe how the range of accountability interventions impacted on internal quality control in the Trust and the network properties of the Trust.

\title{
4.2 External accountability and internal mechanisms for quality control
}

\subsubsection{Information mechanisms}

Our data file shows how the Trust and subgroups of schools within the Trust developed a range of activities over the years aimed at collecting and disseminating information on the quality of its schools. Activities include peer reviews of groups of schools, external reviews of governance of the Trust and of individual schools, and external reviews of how schools spend their pupil premium budget. Centralized monitoring also covered school financial and operational planning, performance data and safeguarding (through visits to schools by central staff). These activities are initiated in response to Ofsted school inspections and the FIs. Over time, those inspections push for a more structured approach to internal quality control, and more centralized monitoring. Performance data are, from year 4, also discussed in termly meetings between the Trust's central team and the $\mathrm{RSC}$, requiring the Trust to have an up to date picture of the performance of their schools on standardized national assessments and in relation to external targets, as described by its CEO:

\begin{abstract}
"Unless we know what's happening in the schools and we've got good data then we can't make judgements and decisions and analyse what's going on in our schools well. This is important because A, to help different schools help each other, but B, because the trustees are held accountable by the Secretary of State for the performance of their schools. You know, we are the most accountable system, externally accountable system, I think, in Europe, in terms of Ofsted inspections, in terms of publications, performance tables, so there's no getting away from it, you know, ministers hold people like me and my trustees to account for how well the accountability works in the trust."
\end{abstract}

In the inspection reports of Celosia academy and Amaryllis academy, comments are made on the accuracy of assessment data. After this, the Trust develops centralized systems for moderating assessments in primary schools and starts implementing systems to track and monitor performance data. In school inspection reports, Ofsted also calls for action plans by the Trust and comments on the suitability of those plans, motivating the Trust to be more specific in their action points and checking the accuracy of (their analysis) of school performance data to inform those actions. Ofsted school inspections impact on the timeline of such changes 
in setting a timeline for the implementation of changes in the inspection report, and through the scheduling of follow-up monitoring visits to check on progress.

Headteachers of Foxglove, Campanula, Nerine and Primrose, and the CEO of the Trust talk about how the FI indicated the need to develop clearer structures and frameworks within the Trust to hold schools to account and how the central staff needed to have a better understanding of "what was happening at grassroots level". The years 4 and 5 annual Trust report (p. 12) describes how the Trust will, in line with recommendations from Ofsted's FI, expand on systems to track and support disadvantaged and vulnerable students in all schools to secure better outcomes for these learners.

The shift from an initial monitoring of financial and operational planning towards increased monitoring of curriculum, teaching and school performance also reflects a natural growth pattern within the Trust. As the years 1 and 2 annual Trust reports explain, incoming schools initially had limited experience in standard accounting procedures, having relied for the most part on local authority financial management. As a result, the Trust had to dedicate time and effort to ensuring that all schools had an effective financial management and reporting system in place. In the early years of the Trust, time and effort also went into managing communication about the opening of new schools with the DfE. As a result, the Trust had a dedicated free school manager on staff. Once the new schools were running and operational and financial systems were established, the Trust directed its efforts towards school improvement and school performance, which was reinforced by the increasing external accountability and monitoring of school and Trust performance.

According to the headteacher of Primrose academy, by year 6, there is a core student performance data system across the Trust developed by schools which includes four annual time points to report data to the Trust, or five time points for schools in special measures. The data is used to look at how pupil premium pupils in one region compare to their non-pupil premium peers, makes comparisons between schools and groups of students, and identifies strengths and weaknesses within and across schools. According to the headteacher of Nerine free school, the Trust included these data in monitoring visits to schools, which started in September year 5, but the headteachers of Campanula and Nerine thought that there was scope for improving the structure of these visits.

Peer review Some of the schools are involved in peer reviews during the course of our study. The years 2 and 3 Annual Reports explain how groups of schools come together in small improvement partnerships, including collaboration between teachers and leaders, joint research projects and school-to-school support. The outcome of reviews is confidential and aims to support the school in improvement by outlining and discussing weaknesses.

The peer reviews generally focused on specific curriculum areas in schools, such as a school's English, Mathematics or Science department, and were highly valued, in some cases one of the reasons for joining the Trust. The headteacher of Primrose academy said that the subject review in her school in September year 4 had great impact as heads were honest with each other,

"our school matters to them as much as the school they're working in because we are one collective entity. And therefore, their investment, not just in the review, but the follow up to that review was great and had a great impact". 
The impact of the review was also high according to the headteacher, because Trust advisers, who lead the review, were held to account for their work in the school through their performance management. The headteacher of Foxglove explains how the peer review had created a culture of openness and collaboration:

"I think the Trust has definitely moved to the fact that the school leaders are as open and honest with the Trust, more so than they would be with an Ofsted inspector where you want to paint the rosy view, whereas the Trust is not seen in that respect. I think there was a feel, you know, three years ago where if everything on paper looked fine you could keep the central team at bay and carry on doing your day job, whereas now it's much more collaborative, and the fact of forced collaboration... you are not allowed to keep your door shut, you need to have people in and stuff."

In cases where the outcome of reviews had not been implemented, headteachers cited a number of reasons, including network-internal issues, where headteachers criticize the skills of the lead reviewer, where the number of participating schools was too big to be effective or a lack of follow-up after the review event. Other reasons are related to the intensive external accountability, particularly for schools who are judged to be "requiring improvement" or "in special measures". These schools receive intensive Ofsted and RSC monitoring and headteachers (Amaryllis, Foxglove, Nerine) explain that schools do not have the time or the capacity to prepare for the peer review on top of the external monitoring, while heads "would not get much out of" participating in peer reviews on top of external inspections and RSC monitoring.

\subsubsection{Control mechanisms}

Centralized control over transactions in the network are enacted by central staff who broker collaboration between schools in the form of support provided by outstanding schools to failing schools, exchange of staff or joint development of staff training. Transactions between the head office and individual schools include the support of schools in difficulty and the internal accountability and monitoring described in the previous section. The membership fees allow the central office to redistribute part of schools' funding to shape transactions both between schools and between the central staff and individual schools.

Schools' Ofsted grades have an impact on the distribution of resources within the Trust through the calculation of these membership fees. The model reflects a strategy where Trust-level support is primarily allocated to schools with failing Ofsted grades who are expected to pay for this support. One of the headteachers however explains that, at the end of year 6 , this strategy is changing towards everybody paying the same membership fee as a percentage of the school budget, according to pupil numbers. This underlines a change in principle where the school's budget is now seen as "Trust money and not school money", according to the headteacher. Support is however, predominantly given to schools with an upcoming inspection visit or schools in special measures. 


\subsubsection{Switching mechanisms}

As previously described, support of schools by the Trust initially focuses on operational and financial issues and gradually moves towards school improvement. Examples of Trust central staff's support of schools are as follows:

- A support programme in areas of statutory and financial compliance

- Support in conversion to an academy

- Dealing with administrative issues around new school buildings

- Applications to open free school

- Financial support of schools in deficit

- Staff training and mentoring, e.g. to develop assessment, teaching and learning in core subjects and leadership and management

- Brokering professional development through teaching schools outside of the Trust.

The Trust actively promotes collaboration between schools by partnering staff from outstanding schools to work alongside schools judged by Ofsted to be inadequate or in special measures. Trust staff are deployed to work in schools struggling to fill vacancies, and the implementation of shared systems (e.g. HR, financial planning, curriculum and assessment) allows schools to exchange staff to plug gaps. Collaboration is reinforced through the peer review programme, but geographical proximity and similarity between schools is an important condition for successful collaboration.

Ofsted inspections of individual schools and the FI have a major impact on the collaboration between schools and in informing the support of schools by central staff. The headteachers of Campanula and Nerine, and the RSC explain how the support of the Trust is primarily allocated to schools judged to be inadequate or requiring improvement by Ofsted ("schools in crisis"), or to schools with an imminent inspection, creating an unequal allocation of resources and an emphasis on the short term.

"so if a school is in special measures or requires improvement, or they [the Trust] are worried about them, you know, everybody and their uncle will be in and checking and helping and making sure, and actually if you are doing $O K$ then it's perhaps perceived as not being a priority, and if resources are limited then you'd, you know, you'd put your resources where they need it most really." (Headteacher of Campanula Academy)

While all schools get termly visits, safeguarding reviews and an analysis of attendance and other data, schools in special measures or with an upcoming Ofsted inspection receive intensive additional help, including an Improvement Board with Trust representatives, leadership training or various forms of in-school support. A corollary of this was a lack of central coordination around CPD or career pathways for all schools, for instance. From year 4/5 (Annual Report) onwards, the Trust started developing a stronger regional structure. The headteacher of Campanula expected this to provide a more sustainable and structured model of school collaboration and support.

Further changes in response to external accountability include the move from external consultants to in-house support for school improvement. Reliance on the 
former was mentioned in an interview with the RSC as an impediment to sustained improvement and as one of the areas for improvement in the FI outcome letter. From year 4/5 onwards, school improvement has been primarily offered in-house by central staff, peers and through working groups, according to the CEO.

\subsubsection{Exclusion mechanisms}

At the start of our study, the MAT takes on a number of schools while also opening up new ones. There was no structured mechanism in place at national level to exclude schools from MATs until RSCs came into office in 2014. They have authority to approve new academy trusts and to assist in the "re-brokering" of some academies from one Trust to another.

During the course of the study, the Trust, in discussion with the respective RSCs, decided to reduce the size of the MAT and reorganize along new regional cluster lines. The intention was to make possible increased school-to-school collaboration. The RSCs enabled the re-brokering of some schools into new MATs.

\subsection{External accountability and changes in network properties}

\subsubsection{Size and composition}

The initial strong push from government for the growth of academies and MATs waned during the time period we cover here. The House of Commons Education Select Committee became concerned over the relationship between schools and their sponsors, leading to a situation where some of the large multi academy sponsors were forced to reduce the number of schools that they were sponsoring and a trend towards smaller groups of three to eight academy schools, working in local groupings as the structure of choice (Talbot 2014).

This trend is also visible in our Trust which sees a pause in growth from January year 4 onwards, with a number of schools being re-brokered into other Trusts, or joining other Trusts. The pause in growth also coincides with the reorganization of the portfolio of schools into regional clusters to better support and consolidate improvement of existing schools (head teacher Primrose, CEO, annual reports years $3 / 4$ and $4 / 5$ ).

The Trust's primary schools are, according to Ofsted, relatively high performing and the secondary schools are more mixed in their performance levels. An explanation for this can be found in the interview with the CEO who says that the Trust has particularly experienced issues in the improvement and support of its secondary academies due to the large and complex scale of these organizations, compared to the smaller primary schools. One of the HMI also explains how the Trust's engagement with secondary schools was much more challenging than support for primary schools: "the secondary phase, in particular, were more stubbornly entrenched; the primaries were willing to have a go, move things forward, the secondary were less so".

Five academies were eventually "re-brokered" into other Trusts. This was prompted by disappointing results from Ofsted inspections and the monitoring of the RSCs. The views of the RSC were central to these decisions. One RSC 
explains that there was a consideration of the extent to which the Trust had the capacity to support and improve the schools, and whether other Trusts might be better placed to provide school support. After some discussion, the decision to rebroker was eventually agreed on a voluntary basis by the Trust.

According to the headteacher of Primrose academy, one of the schools being rebrokered, this analysis did not always offer the best solution as the RSC would only look for a "safe option" in choosing one of the larger MATs, instead of going for a smaller local alternative of a small MAT that had similar systems in place. The Headteacher feels her school was pushed into another large MAT and now has to start over in implementing new systems which she describes as "a setback".

\subsubsection{Governance}

As the Trust grows and the external accountability increases, the governance of schools also changes from shared, decentralized to increasingly centralized and brokered by the central staff. Changes are evidenced in an increased control over school governance, a restructuring of the central staff, the introduction of a regional structure to coordinate collaboration between schools, structuring the performance management of headteachers and clearer schemes of delegation.

These changes follow a natural pattern of growing and maturing networks as described by Provan and Kenis (2008), but as the external accountability tightens over time (e.g. with the start of structured termly meetings with the RSC in year 4), the Trust is also increasingly required to increase the level of control over their schools as is evidenced in the following quote from the CEO:

"I think that when I took up post I would describe the way that the schools had come into the trust as being one where they were encouraged to join, to affiliate to an organisation in a kind of a club type way. Whereas the way in which the government and policy has moved is that the accountability, the lines of accountability, are much more sharper and clearer than they were even two years ago. So the MAT have had to take more central control of their schools, and that's been a very, very difficult cultural change for some of our schools, because that's not the trust that they joined."

Changes in the governance of the Trust follow specific recommendations in Ofsted school and FI reports (e.g. on how the Trust needs to develop systems to monitor school performance and hold teachers and headteachers to account), but examples from other similar MATs who have schools with good Ofsted grades also reinforce centralized control as the most effective improvement strategy for large, nationally organized MATs as is explained by the CEO:

"The trusts that have been the most successful generally have quite a bit of control over the schools they have managed, we think of $X$, we think of $Y$, we think about Z, um... those big secondary trusts where they've said this is the way we do things, have been more successful than the ones where the schools have been left 
to their own devices to get on with things. And so we have moved away from a very loose arrangement between our schools to one which is much tighter and the relationship's much deeper."

The change is characterized in the year $2 / 3$ annual report as a new membership model for schools joining the Trust, with a change in emphasis from "earned autonomy" to "collective responsibility", under which all schools are drawn into the Trust through a regional structure and the establishment of a range of cross-Trust working groups, the latter tasked with the development of shared systems of curriculum planning and assessment.

Regional structure From year 3 onwards, the Trust starts developing a regional structure to address the culture of "firefighting" and create a more long-term approach to school improvement. The need for such a structure is indicated by the disappointing outcomes of several Ofsted inspections. The CEO and headteacher of Amaryllis describe how the Trust started to appoint executive heads who work with two or more schools from year 3 onwards, while an analysis of Annual Reports (years 3-5) shows that the Trust gradually started to move towards a structure of regional hubs (with three to five schools in a hub with an executive head) to allow for a more sustainable structure of accountability and support. Each hub is overseen by an executive head who has, according to the headteacher of Amaryllis, an important role in ensuring that support provided by good and outstanding schools is not "abused".

The CEO of the Trust explained how an executive head has statutory responsibility over the schools and decides on levels of support for each school, depending on the level of expertise and confidence of the headteacher of the school; the executive head is also responsible for the performance management of senior staff in schools. The headteacher of Campanula Academy further explains how the executive head is line managed by members of the trust and governors and how the executive head line manages the school head.

The CEO explains in the interview that each hub would include a mixture of low and high performing schools where a similar scheme of delegation is put in place for each hub to clarify decision-making at the hub and trust level. Each hub only has one governing body and close links to a teaching school that would either be part of the hub or located in the region.

The move towards a regional structure is reinforced in meetings with the RSC who supports the model as being more sustainable. The RSC explains that other large national MATs who have been particularly successful in improving their schools' Ofsted grades have implemented similar structures. An external review, commissioned by the Trust at the end of the year 4 summer term (Annual Report year 4/5), of its internal governance arrangements also informed a restructuring of the Trust into regional hubs.

Shifting from financial/operational control to school improvement and performance Over the years, centralized control of schools has not only increased but also shifted from financial and operational control to school improvement and school performance. The year 4/5 annual report shows centralized: 
- Payroll and HR support;

- Leadership and governance advice;

- Property management;

- Information technology systems;

- Management information system;

- Finance;

- Marketing and communication;

In addition, the headteachers of Foxglove and Primrose academy confirm that all schools are now required to follow the national curriculum (even the free schools who are not required to do so by the DfE) and implement common assessment policies. Some of the policies around curriculum and assessment (e.g. the implementation of common assessments) were initially developed by central staff but not "bought into" by schools; in response, the Trust sets up working groups of schools to develop common approaches which are then discussed and confirmed in joint headteacher meetings. A revision in the schemes of delegation and terms of reference in year 4 confirms and clarifies the responsibilities of headteachers, school governing bodies, the CEO of the Trust and the board of directors.

Changes are also visible in the setup of the central staff. The staff initially included project managers, HR people and finance people who had never worked in schools, and some of the staff were replaced with people with expertise in school improvement after year 4. Years 3-5 see the setting up of new roles to provide educational support for schools: one Primary Phase Leader, one Secondary Phase Leader, one Professional Development Manager, a Data and Impact Manager and new posts in safeguarding, CPD, communications, property management and procurement.

Improvement boards External accountability and particularly Ofsted school inspections also impact on the governance of individual schools. For schools in special measures, the local governing body (which includes a mix of local people) is replaced by Improvement Boards with a greater number of Trust representatives. The Improvement Boards include education professionals from the central staff of the Trust as a strategy to improve schools in an Ofsted category or where Ofsted criticized the governing body in its school inspection report. According to the headteacher of Amaryllis and Primrose academy, dysfunctional governing bodies were not asking the right questions of the headteachers, and were not challenging the headteacher on school improvement and performance data. Ofsted reports indicate the Trust replaced the local governing body in five of their schools to execute more control over schools, but also to become better informed about the support needed.

Headteacher performance management Increased centralized control is also enacted through the performance management of headteachers. The headteachers of Primrose and Amaryllis explain how the Trust has recently developed a common structure for target setting in all schools; targets are now jointly set by the headteacher, the local governors and a senior central staff member. These follow the same outline structure of 
topics and are tweaked so that each school has specific data targets and teaching and learning targets, reflecting their leadership team's performance and unique areas for school improvement. Targets are, according to the headteachers of Amaryllis academy and Foxglove, also set on budget, the school's situation in terms of standards and Ofsted grades, pupil performance, collaboration (working outside of the school and sharing practices) and safeguarding; areas which are also part of the Ofsted school inspection framework.

\section{Conclusion and discussion}

This paper presented a case study of a MAT in England. We explored how the external accountability of schools in the network and of the Trust changes the network over time. Our findings indicate that the combination of accountability activities impact on both the properties of the network and its internal mechanisms of quality control. The most prominent changes are the shift towards more centralized control over, and monitoring of curriculum, assessment and school improvement. Changes also include a pause in the growth of the Trust and the establishment of a regional structure of school collaboration with an executive head who acts as an intermediary between the Trust and a small group of schools.

One of the key findings of our study is the recognition that single-member accountability can prevent network development and motivate a structure of strong hierarchical control around the framework used to hold individual members to account. In our case study, Ofsted school inspections had a dominant role in the external accountability of the MAT, and as such also structured and informed the internal quality control, governance and size of the MAT, particularly in the following ways:

- Support from the Trust and Ofsted "outstanding" or "good" schools is allocated to schools judged to "require improvement" or schools in "special measures", creating a culture of short-termism which constrains the development of more sustainable mechanisms for internal quality control to monitor, support and improve all schools over time

- Distribution of resources is (until year 6) tied to Ofsted school inspection grades where schools in special measures have to pay a higher membership fee

- Schools "requiring improvement" or in "special measures" are monitored more intensively by RSCs and the Trust and more likely re-brokered into other Trusts who have a portfolio of schools with good Ofsted grades

- Head teachers' performance targets are set around Ofsted grades as well as specific standards in the inspection framework

- An important criteria for the allocation of schools to regional hubs is their Ofsted grade, ensuring a mixture of schools with good and failing grades as an indicator of available and required support capacity

- Trusts with a portfolio of overall good/outstanding schools act as good practice examples within the system, and inform the structure and collaboration in other MATs (e.g. regional "hub" structure and centralized monitoring and control) 
- Governing bodies of schools "requiring improvement" or in "special measures" are replaced by Improvement Boards with Trust representatives who have a school improvement background.

These examples indicate how internal quality control in the MAT is focused on the performance of individual schools as measured in Ofsted frameworks, with little development of network-level outcomes that go beyond what is measured and contributes to single school outcomes (such as transitioning of students from primary to secondary).

Similar findings were reported by Sedgwick (2016) who studied the collaboration among a range of publicly funded program service providers. She found that strong single-member accountability has clear implications for the outcomes of the network as a whole as it prevents strong inter-organizational relationships and undermines the integration of missions and tasks, and collaborative service provision. Schools who are predominantly held accountable for their own performance have few incentives to participate in comprehensive joint planning and sharing of risks or to give up autonomy to a network-level authority. A lack of alignment in single-member and network-level accountability creates tensions for particularly high performing schools who have to fulfil both organizational goals (set by single school inspections) and collaborative goals (supporting peers in special measures), thus juggling organizational and collaborative identities (Sedgwick 2016).

Our findings clearly indicate how vertical, one-way, top-down forms of accountability are not supportive of the creation of inter-organizational networks that are agile and flexible enough to effect change. Countries that move towards "network governance" to coordinate their education system need to rethink their education accountability policy and take into account the complexities, interdependencies and dynamics that characterize governance network processes. Given the complex nature of problems and policies with which governance networks deal, their accountability should not be built on standardized pre-set frameworks. Instead, the accountability of networks should, according to Klijn and Koppejan (2014) and Papadopoulos (2014), accept multiple standards and indicators and support the development of peer accountability and network homogeneity.

Ehren et al. (2017) provide a description of such alternative network accountability. They provide examples of how the methodology used by Inspectorates of Education or other "accountees" can capture the mechanisms and conditions that explain the functioning and performance of the network, adapt to local context and the type of networks they are inspecting and create the conditions in which such networks effectively steer themselves. Such approaches would include multiple levels of analysis (individual, interpersonal and collective) at which influence occurs, and use constructivist approaches to develop and test theories of "how something works".

These models feature more subjectivist approaches to valuing and judging the performance and quality of networks, compared to the types of "pass/fail" decisions and standardized evaluation criteria accountees (inspectorates of education) often use. Subjectivist approaches to valuing are more responsive to the object of evaluation and are guided by the meanings people construct in particular places, times and situations, recognizing the dynamic nature of human activity (Christie and Alkin 2013). Stakeholders and users of external accountability (such as schools within a Trust) need to be 
actively involved in making judgements of the outcomes and functioning of the network (Ehren et al. 2017). The involvement of stakeholders ensures that "accountees" (HMI, RSCs) take into account multiple realities when making a value judgement. In such approaches, the locus of judgement moves from the inspector as the primary arbiter of the value a programme or service to facilitating the valuing by others, such as stakeholders and users. Such approaches can be found in "theory-driven evaluation", "comprehensive evaluation" and "programme evaluation", to name a few, and are expected to enhance the overall effectiveness of networks, such as MATs, through a model that is more embedded in the evaluation and learning of the network itself and with closer links to the network-internal mechanisms of quality control. Such external accountability is also expected to promote the integration of schools into the network and support and create new types of network-level outcomes that go beyond the reach of individual schools. Only then will MATs be able to provide more innovative, locally responsive and affordable services to their local communities.

Open Access This article is distributed under the terms of the Creative Commons Attribution 4.0 International License (http://creativecommons.org/licenses/by/4.0/), which permits unrestricted use, distribution, and reproduction in any medium, provided you give appropriate credit to the original author(s) and the source, provide a link to the Creative Commons license, and indicate if changes were made.

\section{References}

Aviram, A. (2003). Regulation by networks. Brigham Young University Law Review, 1179.

Berthod, O., Grothe-Hammer, M., Müller-Seitz, G., Raab, J., \& Sydow, J. (2016). From high-reliability organizations to high-reliability networks: the dynamics of network governance in the face of emergency. Journal of Public Administration Research and Theory, 27(2), 352-371 muw050.

Christie, C. A., \& Alkin, M. C. (2013). An evaluation theory tree. In M. C. Alkin (Ed.), Evaluation roots: a wider perspective of theorists' views and influences (pp. 11-57). Los Angeles: Sage Publications.

Department for Education (2016). Educational Excellence Everywhere. CM9320. https://www.gov. uk/government/uploads/system/uploads/attachment_data/file/508447/Educational_Excellence_ Everywhere.pdf (retrieved November 2016).

Ehren, M. C. M., Janssens, F. J. G., Brown, M., McNamara, G., O'Hara, J., Shevlin, P. (2017). Evaluation and decentralised governance: the case of inspections in polycentric education systems. Journal of Educational Change. http://dx.doi.org/10.1007/s10833-017-9297-9.

Gray, A., Jenkins, B., \& Leeuw, F. (2003). Collaborative government and evaluation: the implications of a new policy instrument. In A. Gray, B. Jenkins, F. Leeuw, \& J. Mayne (Eds.), Collaboration in public services: the challenge for evaluation (pp. 1-29). New Brunswick: Transaction Publishers.

Greany, T., and Ehren, M.C.M. (2016). Written evidence to Education Select Committee inquiry into the performance, accountability and governance of MATs. http://data.parliament. $\mathrm{uk} /$ writtenevidence/committeeevidence.svc/evidencedocument/education-committee/multiacademytrusts/written/32050.html

Hill, R. (2008). Chain reactions. Nottingham: National College for School Leadership.

Hu, Q., Khosa, S., \& Kapucu, N. (2015). The intellectual structure of empirical network research in public administration. Journal of Public Administration Research and Theory, 26(4), 593-612 muv032.

Hutchings, M., Francis, B., \& de Vries, R. (2014). Chain effects: the impact of academy chains on low income students. London: The Sutton Trust.

Janssens, F. J., \& Ehren, M. C. M. (2016). Toward a model of school inspections in a polycentric system. Evaluation and Program Planning, 56, 88-98.

Kenis, P., \& Provan, K. G. (2006). The control of public networks. International Public Management Journal, 9(3), 227-247.

Klijn, E. J., \& Koppejan, J. F. M. (2014). Accountable networks. In M. Bovens, R. E. G. Mark, \& T. Schillemans (Eds.), The Oxford handbook of public accountability (pp. 242-258). Oxford: OUP Oxford. 
Mandell, M., \& Keast, R. (2007). Evaluating network arrangements: toward revised performance measures. Public Performance \& Management Review, 30(4), 574-597.

Mayne, J., \& Rieper, O. (2003). Collaborating for public service quality: the implications for evaluation. In A. Gray, B. Jenkins, F. Leeuw, \& J. Mayne (Eds.), Collaboration in public services: The challenge for evaluation (pp. 105-131). New Brunswick: Transaction Publishers.

Meuleman, L. (2008). Public management and the metagovernance of hierarchies, networks and markets: the feasibility of designing and managing governance style combinations. Springer Science \& Business Media. http://dx.doi.org/10.1007/978-3-7908-2054-6.

Papadopoulos, Y. (2014). Accountability and multi-level governance. In M. Bovens, R. E. G. Mark, \& T. Schillemans (Eds.), The Oxford handbook of public accountability (pp. 273-289). Oxford: OUP Oxford.

Popp, J., MacKean, G., Casebeer, A., Milward, H. B., \& Lindstrom, R. (2014). Inter-organizational networks. A Review of the Literature to Inform Practice. Washington DC: Collaborating Across Boundaries Series.

Provan, K. G., \& Kenis, P. (2008). Modes of network governance: structure, management, and effectiveness. Journal of Public Administration Research and Theory, 18(2), 229-252.

Romzek, B. S. (2000). Dynamics of public sector accountability in an era of reform. International Review of Administrative Sciences, 66(1), 21-44.

Schwartz, R. (2003). The politics of evaluating government collaboration with the third sector. In A. Gray, B. Jenkins, F. Leeuw, \& J. Mayne (Eds.), Collaboration in public services: the challenge for evaluation (pp. 83-105). New Brunswick: Transaction Publishers.

Sedgwick, D. (2016). Building collaboration: Examining the relationship between collaborative processes and activities. Journal of Public Administration Research and Theory, 27(2), 236-252 muw057.

Talbot, A. (2014). Is a new model of school collaboration emerging? http://schoolsweek.co.uk/is-a-newmodel-of-school-collaboration-emerging-academies-studio-schools-utcs-free-schools/ (retrieved November 2016). 